\title{
A New System Converter
}

\author{
Part 1: Tow Cutting on SUMNER's System and its Staple Diagram \\ By Masataka Yamaguchi, Member, TMSJ \\ Department of Textile Engineering, Tokyo Institute of Technology, Tokyo
}

Based on the Journal of the Textile Machinery Society of Japan, Transactions, Vol. 23, No.7/8, T 173-177 (1970)

\begin{abstract}
A new system converter with a revolving circular plate has been devised. The revolving circular cutter is designed to cut a twisting tow along the center axis.

This system can provide a uniform and suitable length of staples for all spinning machines ever in use.

This converter can comply with the currently used tow, e.g., $25 \times 10$ to $400 \times 10$ denier, and produces $28 \mathrm{~mm}$ to $205 \mathrm{~mm}$ length of staples.

This system requires no strictly rigid build.
\end{abstract}

KEY WORDS: CONVERTERS (TOW), TOW FIBER DIAGRAM, STAPLE CUTTERS, TURBOSTAPLER, PACIFIC CONVERTER, TOW TO YARN MACHINES

\section{Introduction}

Tow filaments have uniform thickness and parallel orientation. Methods to make sliver or yarn direct from the tow have been devised to date. There are three types of tow to sliver converters. Direct Spinning System has a problem in the quality of the yarn which is produced by this system. Pacific Converter System awaits the solution of the wearout of cutter and the ill-formation of sliver. Turbo Stapler has problems of the wear-out of tow-gripping roller and irregularity in length of fibers produced by this system.

The author has devised a new converter system with a revolving circular plate to alleviate these defects. This trially-built converter is designed to produce the staple having any mean-length in the range of about 40 to 200 $\mathrm{mm}$, to prevent the draft cutting-without using gripping rollers, free from expensive mending of the wear-outwhich affects spun yarn, and to be simple in mechanism containing drafting apparatus.

For the above reasons, the conventional converter must be improved as follows:

(a) It must be equipped with a special cutter to avoid the draft cutting.

(b) The cutter must be free from such wear-out, low in cost and easily replaceable.

(c) The sliver must be so made that the staples after towcutting may not be scattered about.

(d) The constant diagram must be produced and the irregularity in its thickness must be small.

From the above, the author opines that the best method is to use a revolutional circular plate cutter.

\section{Principle of Cutting Mechanism}

A modification of Sumner's system is illustrated in Fig. 1. II shows the appearance of twisted tow and I the cross-sectional view.

The Sumner's system cuts the twisted tow in full diameter. However, to facilitate mutual cohesion among each staple, the twisted tow has to be cut to the central axis, that is, by radious depth along the tow axis. If cut in radious depth, the tow will be cut with fairly good mutual cohesion among staples at intervals of 1 pitch of the twist according to the twisting angle.

The distribution of the staple length is decided by the diameter of the twisted tow, the twist angle, the strain state of filaments and the spiral structure. The tow must be cut along its axis as soon as the twisting is made and at the same time care should be taken to the stiffness of the tow 


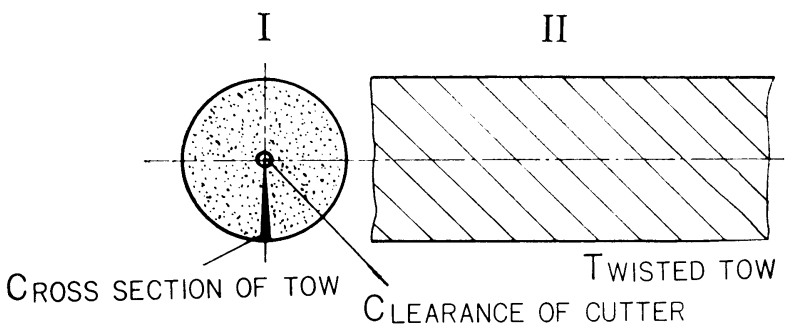

Fig. 1 Part of cut tow

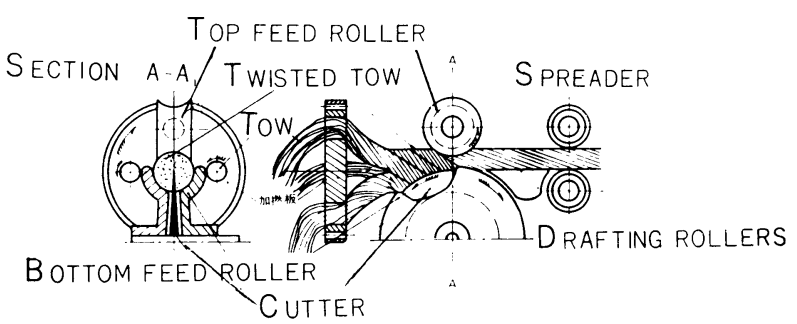

Fig. 2 Cutting mechanism

required for cutting, accordingly, to know the relation between the twist angle and the stiffness.

Fig. 2 illustrates a modified version of the Sumner's system. I shows the front view and II the side view. Tow with suitable thickness is fed from backwards and cut in suitable depth between the couple of rollers containing a rotary circular plate cutter, and drafted in spreading state with spreader after cutting.

\section{Relation between Number of Twists and Cut Length of Staple}

When a single tow is only twisted, the central filament in the tow is kept straight and rotates itself. So it is difficult to cut the filament which lies on the axis of tow, but this problem will be solved later. Regardless of the above problem, let us calculate the relation between the number of twists and staple length. There are many questions that all filaments composing the tow are not perfectly parallel and the inner filaments are shrunk and the outer filaments elongated. The outer layer filaments in the tow have a greater tension. As soon as the tension that stretches the tow is eliminated, the uncut inner filaments moved toward the front roller.

Then, the staple length of each layer after cutting is shown as $S_{i}$ in Fig. 3-1. Fig. 3-II shows the staple length in spread figure in a plain. III is the case where the staple length of 1 pitch circle is same but its period is different from each other. They are complicated in cut length since the length of twist pitch of each layer is different in order to moving due to its elongation or shrinkage.

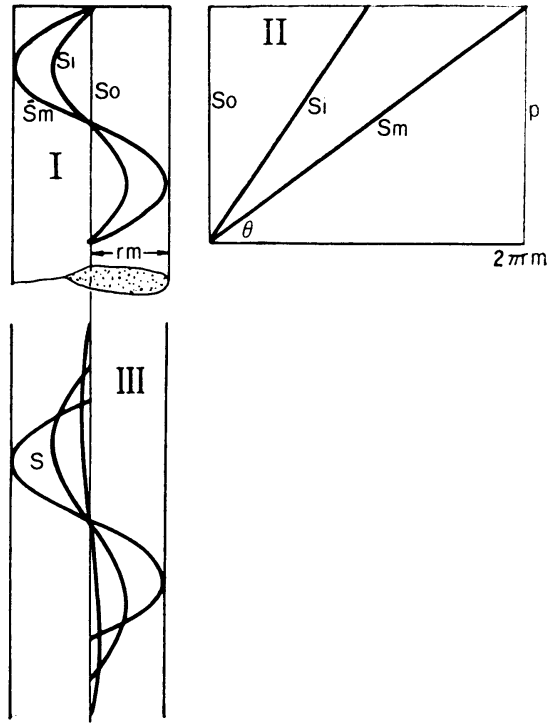

Fig. 3 Cut staple length

In this case, the author considers the type II that has the similar length to the actual structure of tow. If the maximum radius of tow is $r_{m}$ (generally $r_{i}$ ), the periodical length of twisting is $p$, and the maximum twist angle is $\theta_{m}\left(\theta\right.$, generally), then $\quad S_{i}=\sqrt{\left(2 \pi r_{i}\right)^{2}+p^{2}}$

Also if density of filament number $o$ is quite equal every where in the section of tow, the staple diagram can be calculated from both twist angle $(\tan \theta)$ and diameter of tow since the length of staple $S_{i}$ is proportional to $r_{i}$.

Now applying tow $\left(3 d \times 16 \times 10^{3}\right)$ in this case, the range of condition for cutting tow is obtained as follows:

$$
\begin{aligned}
& P: 30-60 \mathrm{~mm} \\
& 2 r_{m}: 12-14 \mathrm{~mm}
\end{aligned}
$$

where

$$
\tan \theta_{m}=0.80-1.36
$$

Consequently the staple diagram is obtained as in Fig. 4. Where, the author tries to compare this result with the actual value applied to cut tow which is well combed (actually free from uncut filaments).

The staple length actually measured is longer than the calculated one in shorter part and shorter than the calculated in the longer part, excepting the part of extreme lengths in staple diagram.

This fact shows that each inner filament which is located in the neighborhood of the axis of tow is crimped by the shrinkage due to twisting, and that on the contrary the filament in the outer side of tow stretches before cutting. So when cutting, the staple recovers its original length.

As to the parts of both extreme lengths of staple diagram in figure, the author considers that specially long staple may be caused due to the movement of cutting point whereas specially short staple (rare as it may be) may be due to 


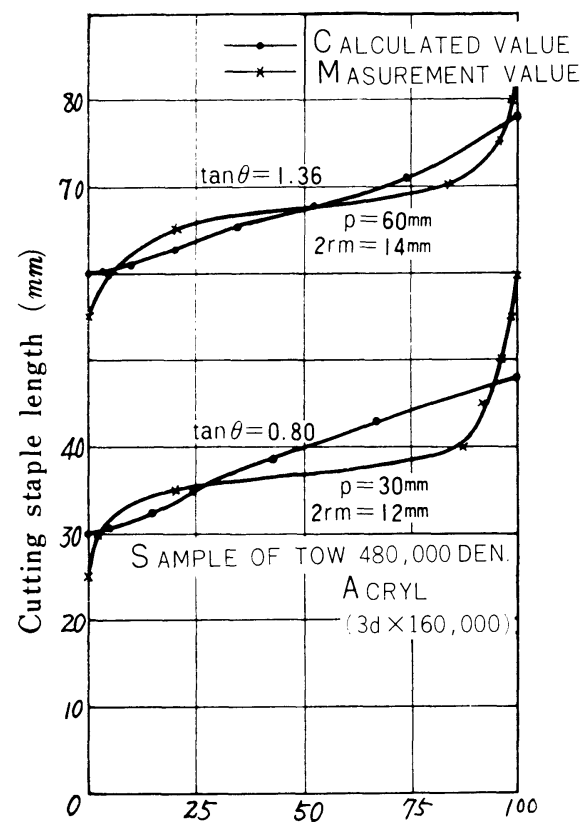

Fig. 4 Staple diagram after cutting

irregularly crimped filament in the neighborhood of tow axis. Then the author tries to investigate the distribution of steple longht of sliver after the tow is cut under the influence of some irregular twisting mechanism or twisting itself.

In this case, the distribution of staple length of sliver after cutting can be calculated from the formula as follows: Putting

$l_{m}$ : maximum staple length

$\left(l_{m}-z\right):$ Staple length

$V z$ : number of sectional staples having length of $\left(l_{m}-z\right)$

$\dot{N}: \quad$ total number of staples in cross section of sliver $f\left(l_{m}-z\right)$ : density function of staple length

then the following formula is obtained:

$$
\nu_{z}=\frac{\dot{N}\left(l_{m}-z\right) f\left(l_{m}-z\right)}{\int_{0}^{l_{m}}\left(l_{m}-z\right) f\left(l_{m}-z\right) d z}
$$

Now replacing $f\left(l_{m}-z\right)$ with $\left(l_{m}-z_{i}\right)$ using discrete variable method,

$$
\left(i_{m}-z_{i}\right)=\frac{\nu_{z i} \cdot \overline{l_{z i}}}{\dot{N}\left(l_{m} \cdot z_{i}\right)}
$$

However, it is found that the maximum difference in each mean length from two formulas is only below $5 \%$.

\section{Relation between Thickness of Tow and Length of Cut Staple}

In order to obtain the fundamental relation between the staple length and thickness, the staple length after cutting for the simply twisted Acryl filament $\left(3 d \times 16 \times 10^{3}\right)$ is calculated. The density of filament number will be

3119-4244 d/mm²

1040-1315 filaments $/ \mathrm{mm}^{2}$

or $1040-1315$ filaments $/ \mathrm{mm}^{2}$

for usual cases.

Supposing that the density of staple number is suitable for cutting tow, then the relation between denier and diameter $\left(2 r_{m}\right)$ of the tow is shown in Fig. 5. Hence, the twisting angle $(\tan \theta)$ takes the range of 0.80 to 1.36 , and the cut length of the staple with the denier and $2 r_{m}$ can be calculated as shown in Fig. 5 .

Consequently, the range between maximum and minimum lengths of staple $\left(S_{o}=p\right)$ is obtained as in Fig. 6 . Althougn this result is only calculated value, actually better result is expected in spinning since the density of staple length takes high value in the neighborhood of mean length of staple as shown in Fig. 4.

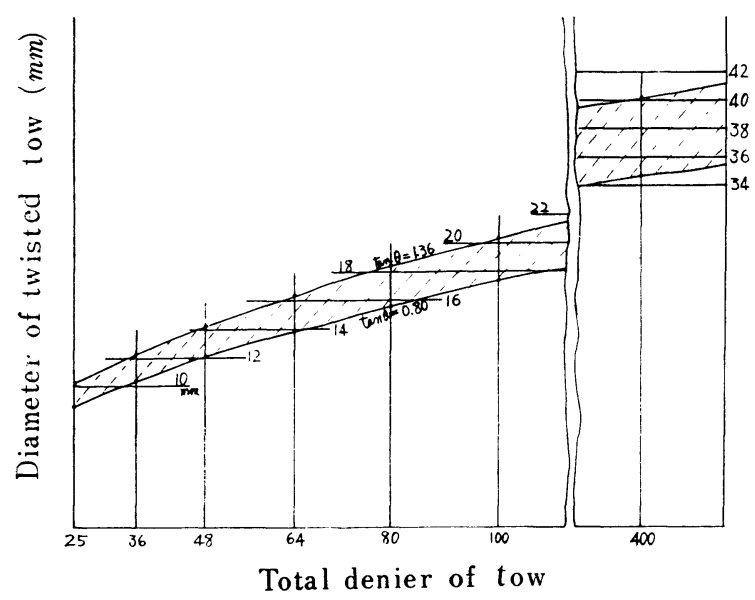

Fig. 5 Relation between total denier of tow and diameter of twisted tow $(\mathrm{mm})$

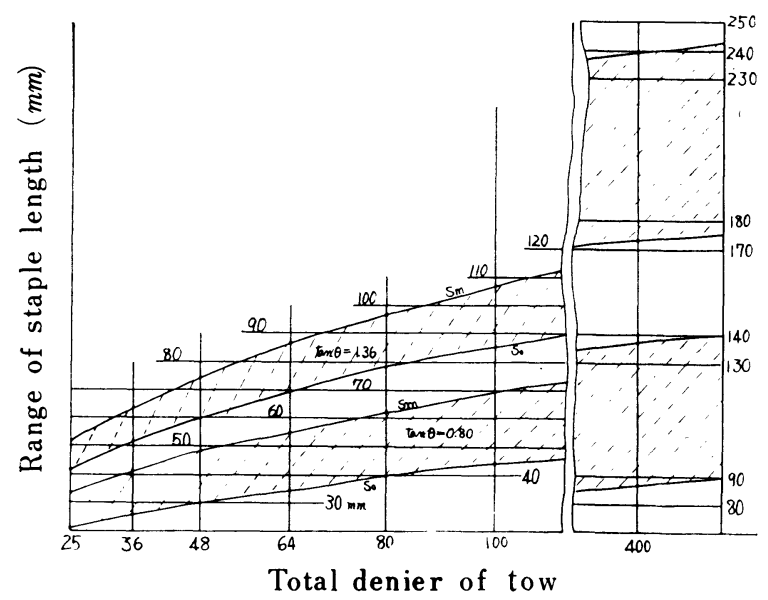

Fig. 6 Relation between total denier of tow and range of staple length $(\mathrm{mm})$ 
Foundamentally, both the number of twists (or $\tan \theta$ ) and the total denier of tow to decide the cut length of staple suitable for the properties of yarn or spinning frame after cutting must be taken into consideration. When the process is settled, the range of staple length available is decided, though its range is generally limited in cutting conditions.

So the length of staple can be adjusted by changing the value of $\tan \theta$ in the range of practical use when the denier of tow is fixed. Then if mean length of staple is assumed as the average of $S_{o}$ and $S_{m}$, the adjustable range of mean value is shown in Table 1 .

Table 1 Variable Range of Mean Length

\begin{tabular}{c|c}
\hline Total denier of tow & $\begin{array}{c}\text { Variable range of } \\
\text { mean length }(\mathrm{mm})\end{array}$ \\
\hline 25 & $26 \sim 46$ \\
36 & $32 \sim 56$ \\
48 & $38 \sim 67$ \\
64 & $46 \sim 78$ \\
80 & $50 \sim 82$ \\
100 & $56 \sim 96$ \\
400 & $110 \sim 205$ \\
\hline
\end{tabular}

This result means that the staple 28 to $205 \mathrm{~mm}$ long can be easily obtained from the two of thickness $25^{4} \times 10$ $400 \times 10^{4}$ denier.

\section{Mechanism of Twisting Tow and Staple Length}

Fundamentally, the distribution of staple length of cut tow is as illustrated above and the calculation method can be applied to many kinds of twisting methods as below.

In the method of twisting around the axis of tow that is mentioned in section 3, the angle of twisting becomes nearly zero to the axis of tow in the neighborhood of it, and therefore, it is considered this causes mis-cutting or irregular staple length. Actually, however, there is no opportunity to occur. Then, the method to avoid the displacement of cutting point of twisted tow fed by the rollers just before the cutting must be considered. Fig. 7 illustrates examples of twisting mechanism including the cases of blend spinning and the other applied methods.

The method $I$ in Fig. 7 is the case of twisting only single tow and the cutting officiency by this method is not high. The method II is the case of twisting several tows in the same time (in this case 4 pieces of tows are twisted) without the first twist. There are no problems if each of A, B, C and d in Fig. 7 is different in material from one another. The method III is the twisted tow having $Z$ twist for the first twist; IV, having $S$ twist for the first twist; $V$, having the mixed twist; VI shows the tow having double layers, for example, using elastic filament for the inside and the other filament for the outside. The method VII is used for perfect cutting and obtaining the olng staple from thin tow.
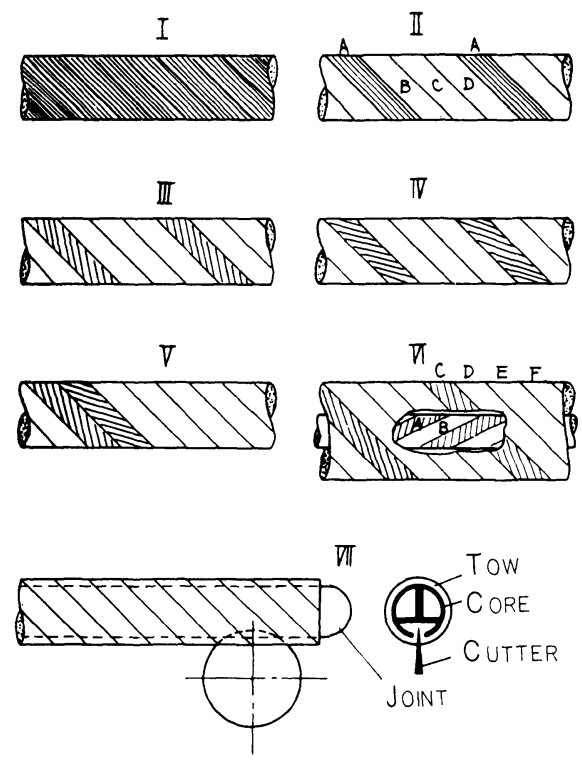

Fig. 7 Various methods of tow twisting mechanism

\section{Conclusion}

In this Sumner's Converter System with a revolutional circular plate cutter which is quite different from the conventional ones, there are two problems, that is, the difficulty in sliver formation and in nipping because of the cutting along the tow axis. From this the author opines that it eases the sliver formation to cut the sliver only by its axis. By this method a suitable staple length can be obtained. And the machine becomes more compact in size and lower in cost because of no compressive cutting and stretch cutting. However, since the tow is twisted just before cutting, the stuffing can having fibers must be controlled exactly for obtaining right twist. But the operation for obtaining the high efficient production may be very difficult. Against the problem the method of oblique or herical cutting can be applied to the mechanism of the twisting and cutting.

When the converter is equipped with drafting device continuously, the problem of low efficiency does not becomes serious in practice. However, there are the following problems to be solved: how to join the ends of tow, what process to be selected after this process, how much ratio of drafting should be used and how much grain of roving should be selected.

As to cutting mechanism with a revolutional circular plate, the systematic design including after-process should be necessary, and the twisting mechanism itself must be improved in future study.

The staple length obtained from the conventional converter is mainly long, but in this new converter system, the sliver consisting of short length staples less than $75 \mathrm{~mm}$ can 
be produced. Therefore, this system can be applied to spinning of any length of staple in the wide range including the cotton spinning system which has high production process.
Moreover, this system can be applied to cutting of many kinds of blended fiber bundle. The system of VI shown in Fig. 7 can be applied to the blend bundle with natural fibers, e.g., core spun yarn. 